Tropical Journal of Pharmaceutical Research July 2019; 18 (7): 1481-1485

ISSN: $1596-5996$ (print); 1596-9827 (electronic)

(C) Pharmacotherapy Group, Faculty of Pharmacy, University of Benin, Benin City, 300001 Nigeria.

\title{
Effect of vasodilator PGE1 on sciatic nerve function, VEGF level, vascular permeability and peripheral nerve in type 2 diabetic rats
}

\author{
Fang Wang ${ }^{1}$, Yufang $\mathrm{Liu}^{2 \star}$, Xiue $\mathrm{Xu}^{3}$, Yuan Chen ${ }^{4}$, Guiyan Chen ${ }^{5}$ \\ ${ }^{1}$ Department of Nuclear Medicine, ${ }^{2}$ Department of Radiology, The People's Hospital of Binzhou, Binzhou 256610, ${ }^{3}$ Department \\ of 3M, Yangxin TCM Hospital of Shandong Province, Yangxin 251800, ${ }^{4}$ Department of Ophthalmology, Wudi People's Hospital, \\ Wudi 251900, ${ }^{5}$ Department of Endocrine, The People's Hospital of Binzhou, Binzhou 256610, China
}

*For correspondence: Email: pcn32z@163.com

Sent for review: 10 May 2019

Revised accepted: 6 July 2019

\begin{abstract}
Purpose: To investigate the effect of vasodilator prostaglandin E1 (PGE1) on sciatic nerve function, vascular endothelial growth factor (VEGF), vascular permeability and peripheral nerve in type 2 diabetes mellitus (T2DM) rats.

Methods: Twenty-one rats in the study group were intraperitoneally injected with PGE1, while rats in T2DM untreated group $(n=21)$ were injected with an equivalent amount of normal saline. Seven rats were randomly selected from the study and the control groups every seven days for 21 days for determination of changes in sciatic nerve function, VEGF level, vascular permeability and peripheral nerves.

Results: Sciatic nerve motor nerve conduction velocity (MNCV) was significantly higher in the study group than in T2DM untreated control group at the three time-points post-treatment $(p<0.01)$. The level of VEGF in the study group decreased, relative to the T2DM untreated control group on the 7th 14th and 21 st days post- treatment $(p<0.05)$ while the water content of sciatic nerve tissue in study group was markedly decreased, relative to control value on day $21(p<0.05)$. Rats in the study group showed decreased TTT, relative to those in T2DM untreated group on days 7,14 and 21 post-treatment $(p<$ 0.01).

Conclusion: PGE1 improves the sciatic nerve function of T2DM rats, reduces the level of serum VEGF and vascular permeability, and protects peripheral nerves. These findings provide a basis for the development of new T2DM drugs.
\end{abstract}

Keywords: Prostaglandin E1 (PGE1), Type 2 diabetes, Sciatic nerve function, VEGF, Vascular permeability, Peripheral nerve

This is an Open Access article that uses a fund-ing model which does not charge readers or their institutions for access and distributed under the terms of the Creative Commons Attribution License (http://creativecommons.org/licenses/by/4.0) and the Budapest Open Access Initiative (http://www.budapestopenaccessinitiative.org/read), which permit unrestricted use, distribution, and reproduction in any medium, provided the original work is properly credited.

Tropical Journal of Pharmaceutical Research is indexed by Science Citation Index (SciSearch), Scopus, International Pharmaceutical Abstract, Chemical Abstracts, Embase, Index Copernicus, EBSCO, African Index Medicus, JournalSeek, Journal Citation Reports/Science Edition, Directory of Open Access Journals (DOAJ), African Journal Online, Bioline International, Open-J-Gate and Pharmacy Abstracts

\section{INTRODUCTION}

Diabetes mellitus (DM) is a metabolic disease which manifests in fasting hyperglycemia due to deficiency in insulin production or insulin insensitivity. With economic development, aging population and changes in people's living standards, type 2 diabetes mellitus (T2DM) 
cases are on the increase year by year, especially in developing countries [1]. Diabetes mellitus (DM) now ranks third among noncommunicable diseases that threaten people's lives and health. Diabetic peripheral neuropathy (DPN) refers to the symptoms associated with peripheral nerve dysfunction in patients with DM when other causes are excluded [2]. It is a microvascular disease which damages the axonal cord, myelin sheath or Schwann cell. It is one of the most common complications of T2DM, manifested mainly as increased blood glucose, increased blood viscosity, and changes in platelet function [3]. Studies have shown that during $\mathrm{DM}$, the basement membrane is thickened, the lumen is narrowed, vascular permeability increases, and the conduction velocity of peripheral nerve function slows down [4]. Vascular endothelial growth factor (VEGF) promotes vascular regeneration. Diabetes mellitus (DM) increases the level of VEGF and vascular permeability. High VEGF level is associated with diabetic nephropathy and diabetic retinopathy [5].

Prostaglandin E1 (PGE1), a bioactive substance widely present in vivo, inhibits platelet agglutination, reduces platelet hyperactivity and thromboxane $A_{2}\left(T X A_{2}\right)$ level, and inhibits platelet activation [6]. It reduces free $\mathrm{Ca}^{2+}$ levels in vascular smooth myocytes, blocks norepinephrine release from vascular sympathetic nerve terminals, and enhances relaxation of vascular smooth muscles, thereby improving microcirculation and the speed of nerve conduction. Prostaglandin E1 (PGE1) has a good effect on the enhancement of nerve function in the treatment of DPN [7]. The aim of this study was to investigate the effects of PGE1 on sciatic nerve function, VEGF level, vascular permeability and peripheral nerve in T2DM rats.

\section{EXPERIMENTAL}

\section{Animals and establishment of T2DM rat model}

Forty-nine (49) healthy SD male rats of clean grade (mean weight, $210 \pm 40 \mathrm{~g}$ ) were raised at $19 \pm 3{ }^{\circ} \mathrm{C}$ and $58 \pm 12 \%$ humidity, with free access to feed and drinking water, and fed adaptively for 3 weeks. The rats were intraperitoneally injected with streptozotocin (60 $\mathrm{mg} / \mathrm{kg}$ ), and blood glucose was measured 3 days later. Rats with blood glucose values greater than $11.1 \mathrm{mmol} / \mathrm{L}$ were selected as model T2DM rats.

This research was approved by the Animal Ethical Committee of Department of Radiology, the People's Hospital of Binzhou, Binzhou
256610, China (approval no. 201813581), and was conducted in keeping with "Principles of Laboratory Animal Care" [8].

\section{Animal grouping}

Forty-two T2DM rats were randomly divided into two groups using the random number table method: study group and T2DM untreated control group (control group), with 21 rats in each group. A group of 7 randomly selected rats served as normal group. Rats in the study group were intraperitoneally injected with PGE1 (Xi'an Libang Pharmaceutical Co. Ltd). PGE1 injection was diluted to $20 \mathrm{~mL}$ and given at a dose of 3.2 $\mathrm{mL} / \mathrm{kg}$ body weight once a day. Rats in the control group were injected with an equivalent volume of normal saline in place of PGE1, while rats in normal group were untreated. Seven rats were randomly selected from the study group and the untreated T2DM control group every seven days, i.e., on the $7^{\text {th }}, 14^{\text {th }}$ and $21^{\text {st }}$ days post-treatment, for the determination of changes in sciatic nerve function, VEGF level, vascular permeability and peripheral nerves.

\section{Main reagents and instruments}

Blood sugar meter and test paper were provided by Aikang Biotechnology Co. Ltd Ultralow temperature refrigerator was purchased from GuanYa Constant Temperature Refrigeration Technology Co. Ltd. Aseptic ultrafilter was product of Tianjin Sailisi Automation Technology Co., Ltd. Centrifuge was provided by Changsha Xiangrui Centrifuge Co. Ltd. Streptozotocin was purchased from Sigma S0130. Citric acid buffer (adjusted to $\mathrm{pH} 4.2$ - 4.5) was prepared by mixing equimolar amounts of citric acid and sodium citrate). ELISA kit was product of Thermo Fisher Scientific Co. Ltd, while PGE1 injection was purchased from Xi'an Libang Pharmaceutical Co., Ltd. Drying box was purchased from Shanghai Shanzhi Instrument Equipment Co. Ltd.

\section{Evaluation of sciatic nerve function}

Each rat was placed in a prone position, and stimulation electrodes were inserted into the left sciatic notch. Then, two pairs of recording electrodes were inserted into the left ankle and two toes of the left foot so as to record the motor nerve conduction velocity (MNCV) of the sciatic nerve.

\section{Determination of VEGF}

Abdominal aorta blood $(4 \mathrm{~mL})$ was taken from each rat, and the serum and blood cells were 
separated by centrifugation. The level of VEGF was determined using immunohistochemical method.

\section{Evaluation of vascular permeability}

Sciatic nerve from rat left femur was used. Approximately $3 \mathrm{~cm}$ of the sciatic nerve was weighed in the wet and dry states. The water content of sciatic nerve tissue was measured using Eq 1.

$W C(\%)=[(w w-d w) / w w] \times 100$

where $W C$ is water content, $w w$ is wet weight and $d w$ is dry weight.

\section{Evaluation of tailflick threshold temperature}

Each rat was fixed with the tail drooping naturally into water of appropriate temperature. The temperature of the rat tail when it was removed from the water was recorded as the tailflick threshold temperature (TTT).

\section{Statistical analysis}

All statistical analyses were carried out with SPSS version 21.0 software package. Measurement data were compared using independent sample $t$-test; counting data were compared with $x^{2}$ test, while ranked data were compared using Ridit test. Values of $p<0.05$ were taken as indicative of statistical significance.

\section{RESULTS}

\section{Sciatic nerve function of rats}

As shown in Table 1, the sciatic nerve motor nerve conduction velocity (MNCV) values in the study group and the untreated T2DM control group were significantly low, relative to normal control $(p<0.01)$. However, MNCV of sciatic nerve was markedly higher in study group than control values at the 3 time points after treatment $(p<0.01)$.

\section{VEGF levels in the rat groups}

Table 2 shows that, compared with the normal group, there were markedly higher VEGF levels in rats in study group and untreated T2DM control $(p<0.05)$. Lower VEGF values were seen in the study group, when compared with control on days 7, 14 and 21 after treatment $(p<$ 0.05 ). There was positive expression of VEGF in the sciatic nerve fiber axis of rats in the three groups on days 7, 14 and 21 after treatment, but there was no VEGF expression in Schwann cells and myelin sheath.

Table 1: Sciatic nerve function MNCV rats (mean \pm $\mathrm{SD}, \mathrm{n}=7$ )

\begin{tabular}{|c|c|c|c|}
\hline \multirow[t]{2}{*}{ Group } & \multicolumn{3}{|c|}{$\begin{array}{c}\text { MNCV } \\
(\mathrm{m} / \mathrm{s})\end{array}$} \\
\hline & Day 7 & Day 14 & Day 21 \\
\hline Normal control & $\begin{array}{l}43.91 \pm \\
0.24\end{array}$ & - & 一 \\
\hline $\begin{array}{l}\text { Untreated T2DM } \\
\text { control }\end{array}$ & $\begin{array}{c}36.47 \pm \\
0.26\end{array}$ & $\begin{array}{c}34.11 \pm \\
1.02\end{array}$ & $\begin{array}{c}32.34 \pm \\
0.18\end{array}$ \\
\hline Study & $\begin{array}{c}37.68 \pm \\
0.57\end{array}$ & $\begin{array}{c}35.78 \pm \\
0.46\end{array}$ & $\begin{array}{c}33.22 \pm \\
0.18\end{array}$ \\
\hline$F / t$ & 43.63 & 3.949 & 9.146 \\
\hline$P$-value & $<0.001$ & 0.002 & $<0.001$ \\
\hline
\end{tabular}

Table 2: VEGF levels of rats (mean $\pm S D, n=7$ )

\begin{tabular}{lccc}
\hline \multirow{3}{*}{ Group } & \multicolumn{3}{c}{$\begin{array}{c}\text { VEGF level } \\
(\mathbf{n g} / \mathbf{m L})\end{array}$} \\
\cline { 2 - 4 } & Day 7 & Day 14 & Day 21 \\
\hline Normal group & $36.54 \pm$ & - & - \\
Untreated & 9.98 & & $91.52 \pm$ \\
T2DM control & $67.13 \pm$ & $76.58 \pm 1.01$ & 1.51 \\
Study & 1.18 & & $83.78 \pm$ \\
$F / t$ & $62.48 \pm$ & $70.73 \pm 1.68$ & 2.23 \\
$P$-value & 3.97 & 7.896 & 7.604 \\
\hline
\end{tabular}

\section{Vascular permeability of rats}

There was significantly higher water contents of sciatic nerve in the study and the untreated T2DM control groups than in normal control, indicating significant increase in vascular permeability $(p<0.05)$. Although there was lower water content in the study group than in untreated T2DM control on the $7^{\text {th }}$ and $14^{\text {th }}$ days after treatment, water contents in the two groups were comparable $(p>0.05)$. The water content of sciatic nerve tissue in the study group was significantly lower than that in the control group on day 21 after treatment, i.e. vascular permeability in the study group was significantly lower than that in the control group on day 21 ( $p$ $<0.05)$. These results are shown in Table 3.

Table 3: Vascular permeability ( $\%$, mean $\pm S D, n=7$ )

\begin{tabular}{lccc}
\hline Group & $\begin{array}{c}\text { Day 7 } \\
(\%)\end{array}$ & $\begin{array}{c}\text { Day 14 } \\
(\%)\end{array}$ & $\begin{array}{c}\text { Day 21 } \\
\text { (\%) }\end{array}$ \\
\hline Normal control & $57.46 \pm$ & - & - \\
Untreated T2DM & 6.93 & & - \\
control & $5.57^{*}$ & 1.98 & 2.27 \\
Study & $64.27 \pm$ & $73.15 \pm$ & $78.29 \pm$ \\
& $5.31^{*}$ & 2.81 & 1.36 \\
\hline${ }^{*} P$ & 0.05, compared to normal control
\end{tabular}

${ }^{\star} P<0.05$, compared to normal control 


\section{Peripheral nerve differences amongst rat groups}

There were higher values of tailflick threshold temperature (TTT) in the study and untreated T2DM control rat groups than in normal control rats $(p<0.01)$. However, the TTT of rats in the study rats decreased following treatment, when compared with that of rats in the untreated T2DM control on days 7, 14 and 14 post-treatment $(p<$ 0.01). These results are shown in Table 4.

Table 4: TTT of rats $\left({ }^{\circ} \mathrm{C}\right.$, mean $\left.\pm \mathrm{SD}, \mathrm{n}=7\right)$

\begin{tabular}{|c|c|c|c|}
\hline Group & $\begin{array}{c}\text { Day } 7 \\
\left({ }^{\circ} \mathrm{C}\right)\end{array}$ & $\begin{array}{l}\text { Day } 14 \\
\left({ }^{\circ} \mathrm{C}\right)\end{array}$ & $\begin{array}{c}\text { Day } 21 \\
\left({ }^{\circ} \mathrm{C}\right)\end{array}$ \\
\hline Normal control & $\begin{array}{c}42.54 \pm \\
0.11\end{array}$ & - & - \\
\hline $\begin{array}{l}\text { Untreated T2DM } \\
\text { control }\end{array}$ & $\begin{array}{l}44.09 \pm \\
0.17\end{array}$ & $\begin{array}{l}44.31 \pm \\
0.16\end{array}$ & $\begin{array}{c}44.58 \pm \\
0.26\end{array}$ \\
\hline Study & $\begin{array}{c}43.78 \pm \\
0.21\end{array}$ & $\begin{array}{c}43.82 \pm \\
0.34\end{array}$ & $\begin{array}{c}44.01 \pm \\
0.38\end{array}$ \\
\hline$F / t$ & 66.19 & 3.451 & 3.275 \\
\hline$P$-value & $<0.001$ & 0.005 & 0.007 \\
\hline
\end{tabular}

\section{DISCUSSION}

Diabetes mellitus (DM) is a chronic, progressive and lifelong disease caused by a variety of factors such as impaired insulin uptake and insulin resistance. It causes damage to the heart, blood vessels and nerves, thereby threatening the survival of patients $[9,10]$. Prostaglandin E1 (PGE1) is a vasodilator that reduces peripheral resistance through enhancement of cyclic adenosine monophosphate (cAMP) levels in vascular smooth muscle cells. Moreover, it promotes the reduction of activated platelets around thrombus, mitigates deformability of erythrocytes, and improves microcirculation [11]. The present study was carried out to unravel the influence of PEG1 on sciatic nerve function, VEGF level, vascular permeability and peripheral nerve in T2DM rats.

The sciatic nerve is the largest nerve in the body. It is composed of tibial nerve and nervus peroneus communis, and it manages the sensation and movement of the lower extremity $[12,13]$. The most commonly used index for assessing peripheral nerve function in DM is nerve conduction velocity. This index is an effective parameter that reflects the function of myelinated nerve fibers. In addition, it reflects the presence of diabetic peripheral neuropathy (DPN). Tailflick threshold temperature (TTT) reflects the transmission of thermal injury stimulation in the sensory nerve fibers of SD rats [14].
In this study, values of sciatic nerve MNCV in the study rats and the untreated T2DM control rats were markedly lowered, relative to normal control rats, and study group sciatic nerve MNCV was significantly increased, when compared to that of untreated T2DM control rats on $7^{\text {th }}, 14^{\text {th }}$ and $21^{\text {st }}$ days post-treatment. Higher TTTs were seen in the study and untreated T2DM rats than that in normal rats, and the TTT of the rats in the study group was markedly lower than the corresponding values in untreated T2DM rats on the $7^{\text {th }}, 14^{\text {th }}$, and $21^{\text {st }}$, days after treatment. These results indicate that the nerve conduction velocity of T2DM rats was decreased, and that the response to pain was weakened. This implies that the nerve function of the rats was damaged to some extent, while the increase in MNCV after treatment indicated that PGE1 exerted a certain repair effect on the nerve fibers.

In a previous study, it was found that serum VEGF levels in DM individuals were markedly higher than in healthy controls [15]. Vascular endothelial growth factor (VEGF) is a heparinbinding protein unique to cells of the vascular endothelium. It induces the proliferation of vascular endothelial cells and promotes vascular regeneration. Ischemia, hypoxia and hyperglycemia stimulate the secretion of VEGF. Increased levels of VEGF lead to increased vascular permeability and severe damage to peripheral nerve function [16]. The results of this study showed that, compared with the normal group, higher VEGF levels were seen in the study group and the untreated T2DM control group, relative to healthy rats, while there was lower VEGF in the study group than in healthy control rats on days 7,14 and 21 after treatment.

The higher water content of sciatic nerve in the study and untreated T2DM rats implies increased vascular permeability. Vascular permeability of study rats was significantly decreased on day 21 . These results indicate that VEGF level is positively correlated with vascular permeability, and that PGE1 reduces vascular permeability by decreasing VEGF levels, thereby preventing further destruction of peripheral nerve tissue.

\section{CONCLUSION}

These results indicate that the MNCV of sciatic nerve in T2DM rats is significantly lower than that in normal control rats, and that serum VEGF, TTT and vascular permeability significantly increase, leading to the destruction of the structure of peripheral nerves. However, administration of the vasodilator PGE1 to T2DM rats significantly increases the MNCV of sciatic nerve, and significantly decreases serum VEGF, TTT and 
vascular permeability, thereby improving peripheral nerve function. Therefore, PGE1 reduces serum VEGF levels and vascular permeability. It improves sciatic nerve function and repairs peripheral nerve tissue. However, further research should be carried out to validate these findings.

\section{DECLARATIONS}

\section{Conflict of interest}

No conflict of interest is associated with this work.

\section{Contribution of authors}

We declare that this work was done by the author(s) named in this article and all liabilities pertaining to claims relating to the content of this article will be borne by the authors. All authors read and approved the manuscript for publication. Yufang Liu conceived and designed the study, Fang Wang, Yufang Liu, Xiue Xu, Yuan Chen, Guiyan Chen collected and analysed the data, while Fang Wang wrote the manuscript.

\section{Open Access}

This is an Open Access article that uses a funding model which does not charge readers or their institutions for access and distributed under the terms of the Creative Commons Attribution License (http://creativecommons.org/licenses/by/ 4.0) and the Budapest Open Access Initiative (http://www.budapestopenaccessinitiative.org/rea d), which permit unrestricted use, distribution, and reproduction in any medium, provided the original work is properly credited.

\section{REFERENCES}

1. Wang $W$, Wang $L$, Guo $D$, Suo $L N$, Zhang $W$. Liraglutide's Effect on the Level of MDA and GSH-Px in Obesity Type 2 Diabetic Patients. J China Med Univ 2015; 44(1): 84-85.

2. Shi $X H$, Chen $Y H$, Zhou $L H$. The relationship of hyperhomocysteinemia and diabetic neuropathy. Chin J Diabetes 2017; 16(6): 331-333.

3. Vileikyte L, Leventhal H, Gonzalez JS, Peyrot M, Rubin $R R$, Ulbrecht JS, Garrow A, Waterman C, Cavanagh $P R$, Boulton AJ. Diabetic Peripheral Neuropathy and Depressive Symptoms. Diabetes Care 2015; 28(10): 2378-2383.
4. Yuan $F$, Dellian $M$, Fukumura $D$, Leunig $M$, Berk $D A$, Torchilin VP, Jain RK. Vascular permeability in a human tumor xenograft: molecular size dependence and cutoff size. Cancer Res 2015; 55(17): 3752-3756.

5. Zhang YN, Xu CJ, Su GY, Xu C, Gao LX, Liu GH, Zhu $T N$, Zhou WH. Influences of ACE inhibitors on renal expression of vascular endothelial growth factor in experimental type 2 diabetic rats. Hebei Med J 2016; 31(11): 1301-1304.

6. Kreutz RP, Nystrom $P$, Kreutz $Y$, Miao J, Kovacs $R$, Desta Z, Flockhart DA, Jin Y. Inhibition of platelet aggregation by prostaglandin E1 (PGE1) in diabetic patients during therapy with clopidogrel and aspirin. Platelets 2013; 24(2): 145-150.

7. Tang JR, Ding $X S$, Zhang $K Z$, Su JH, Zhang $P$, Zhu XJ, $W u L$, Xiao $H$. Influences on Expression of VEGF and Pathologic Changes by Improvement of Microcirculation Following Crushing Lesion of Sciatic Nerve in Rats. Chin J Clin Neurosci 2017; 15(4): 348-352.

8. World Health Organization. Principles of laboratory animal care. WHO Chron 1985; 39: 51-56.

9. Whiting DR, Guariguata L, Weil C, Shaw J. IDF diabetes atlas: global estimates of the prevalence of diabetes for 2011 and 2030. Diabetes Res Clin Pract 2016; 94(3): 311-321.

10. Petrie JR. Follow-up of intensive glucose control in type 2 diabetes. New Eng J Med 2017; 360(4): 417.

11. Guo HW, Wang XH, LiU TS, LiU DY. Effect of alprostadil injection on serum VEGF and NES in patients with early stage type 2 diabetic retinopathy. Chin J Difficult Complicated Cases 2014; (2): 153-155.

12. Liu XH, Mai WL, Zheng $Q$, Liu H, Jing HE, Chen DB. Effects of proanthocyanidins on nerve conduction velocity of type 2 diabetes rats. J North Sichuan Med College 2014; (5): 429-431.

13. Mathews KS, Wark HAC, Normann RA. Assessment of rat sciatic nerve function following acute implantation of high density utah slanted electrode array (25 electrodes $/ \mathrm{mm} 2$ ) based on neural recordings and evoked muscle activity. Muscle Nerve 2015; 50(3): 417424.

14. Wick $D E$, Roberts $S K$, Basu A, Sandroni P, Fealey RD, Sletten D, Charkoudian N. Delayed threshold for active cutaneous vasodilation in patients with Type 2 diabetes mellitus. J Appl Physiol 2016; 100(2): 637.

15. Mo FF, Liu W, Huang SQ, Li YB, Hu GT, Wu HM, Wang $H L$. Experimental study of alprostadil on peripheral nerve function and nutrient vessel permeability in diabetic rats. J Pract Med Tech 2017; 24(2): 138-141.

16. Porojan MD, Cătană $A$, Popp RA, Dumitrascu DL, Bala C. The role of NOS2A $-954 \mathrm{G} / \mathrm{C}$ and vascular endothelial growth factor $+936 C / T$ polymorphisms in type 2 diabetes mellitus and diabetic nonproliferative retinopathy risk management. Ther Clin Risk Manag 2015; 11: 1743-1748. 